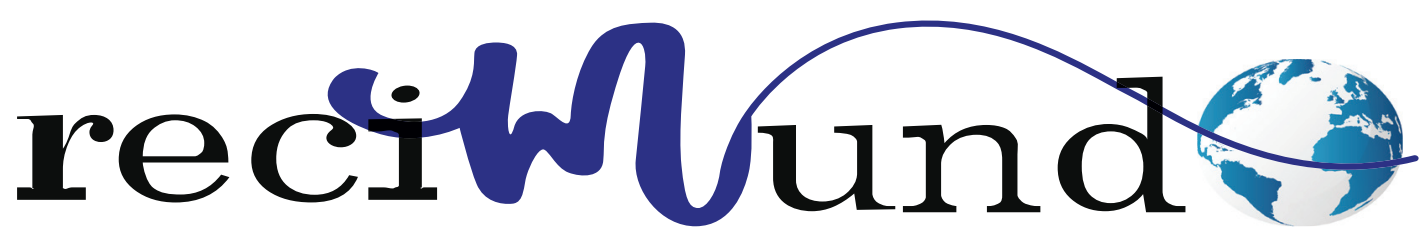

Revista Científica Mundo de la Investigación y el Conocimiento

DOI: 10.26820/recimundo/4.(2).mayo.2020.53-63

URL: http://recimundo.com/index.php/es/article/view/822

EDITORIAL: Saberes del Conocimiento

REVISTA: RECIMUNDO

ISSN: 2588-073X

TIPO DE INVESTIGACIÓN: Artículo de Revisión

Código UNESCO: 32 Ciencias Médicas; 3201 Ciencias Clínicas

PAGINAS: 53- 63

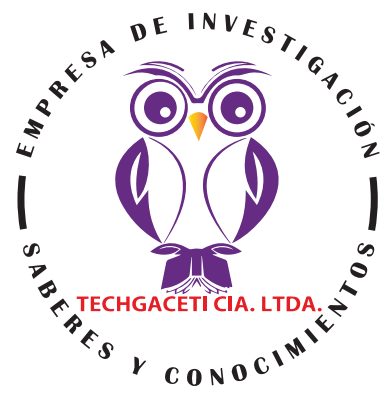

\title{
Leucemia linfoblástica aguda diagnostico
}

Acute lymphoblastic leukemia diagnosis

Diagnóstico de leucemia linfoblástica aguda

María José Mancero Rodríguez'; Karolina De la Paz Arellano Salinas;

Kristopher Alexander Santo Cepeda3; Marco Esteban Rodríguez Revelo ${ }^{4}$

RECIBIDO: 15/03/2020 ACEPTADO: 20/03/2020 PUBLICADO: 20/05/2020

1. Medico; Investigador Independiente; Guayaquil, Ecuador; majosma8@hotmail.com; (D) https://orcid.org/00000001-5984-3895

2. Medico; Investigador Independiente; Guayaquil, Ecuador; karitoarellano.md@gmail.com; (D) https://orcid.org/0000-0003-3041-846X

3. Medico; Investigador Independiente; Guayaquil, Ecuador; kristophersanto@hotmail.com; $\mathbb{D}$ https://orcid.org/0000-0002-9543-886X

4. Médico Cirujano; Investigador Independiente; Guayaquil, Ecuador; marco.rodrev@gmail.com; (D) https://orcid. org/0000-0003-3403-3743

CORRESPONDENCIA

María José Mancero Rodríguez

majosma8@hotmail.com

Guayaquil, Ecuador

๑ RECIMUNDO; Editorial Saberes del Conocimiento, 2020 


\section{RESUMEN}

En la Leucemia Linfoblástica Aguda, también conocida como Leucemia Linfocítica/Linfoide Aguda (LLA/ALL) la categoría «linfocítico» hace referencia a que esta patología se origina de los linfocitos en sus formas tempranas (inmaduras), es decir, de un tipo de glóbulo blanco que se reproduce excesivamente, afectando a dos tipos de linfocitos (las células B y las células T); mientras que «aguda», quiere decir que es posible que la leucemia evolucione rápidamente, y que, de no ser tratada, probablemente resulte mortal en poco tiempo. Se trata del cáncer más común en pediatría; pero igualmente afecta a adultos de todas las edades. En edad pediátrica, esta enfermedad es la neoplasia más común, representando entre el 75 y $80 \%$ de todas las leucemias agudas. Su incidencia ha podido determinarse con pico máximo entre los 2 y 5 años de edad. Con la presente revisión bibliográfica se pretende mencionar cuáles son los métodos diagnósticos de la LLA, no sin antes hacer referencia de algunas acepciones sobre dicha patología, sus factores de riesgo y síntomas y manifestaciones clínicas. Los resultados obtenidos están constituidos por las exposiciones que varios expertos han hecho sobre este tema, y los mismos satisfacen el objetivo propuesto. En conclusión, por una parte se infiere que en los últimos años las opiniones respecto a los métodos diagnósticos de LLA son más coincidentes de disidentes entre la mayoría de los tratadistas ya que, básicamente, estos se vinculan a análisis de sangre (Hemograma completo y frotis de sangre periférica), un aspirado y biopsia de médula ósea (también llamado mielograma) y una punción lumbar; sin menoscabo de las otras pruebas que igualmente coadyuvan con dicha diagnosis, pero mucho más con la fase terapéutica. Sin perjuicio de esto, igualmente fue posible identificar algunas recomendaciones que se deben considerar al momento de procurar un diagnóstico de LLA.

Palabras clave: Linfocítica, neoplasia, patología, hemograma, mielograma.

\section{ABSTRACT}

En la Leucemia Linfoblástica Aguda, también conocida como Leucemia Linfocítica / Linfoide Aguda (LLA / ALL) glóbulo blanco que se reproduce excesivamente, afectando a dos tipos de linfocitos (las células B y las células T); mientras que "aguda», quiere decir que es posible que la leucemia evolucione rápidamente, y que, de no ser tratada, probablemente resulte mortal en poco tiempo. Se trata del cáncer más común en pediatría; pero igualmente afectaciones a adultos de todas las edades. En edad pediátrica, esta enfermedad es la neoplasia más común, representando entre el 75 y el $80 \%$ de todas las leucemias agudas. Su incidencia ha determinado determinar con pico máximo entre los 2 y 5 años de edad. Con la presente revisión bibliográfica se pretende identificar las respuestas son los métodos diagnósticos de la LLA, no sin antes hacer referencia de algunas acepciones sobre dicha patología, sus factores de riesgo y síntomas y manifestaciones clínicas. Los resultados obtenidos están constituidos por las exposiciones que varios expertos han hecho sobre este tema, y los mismos satisfacen el objetivo propuesto. En conclusión, por una parte se infiere que en los últimos años las opiniones respecto a los métodos diagnósticos de LLA son más coincidencias de disidentes entre la mayoría de los tratadistas que, específicamente, estos se vinculan un análisis de sangre (Hemograma completo y frotis de sangre periférica), un aspirado y biopsia de médula ósea (también llamado mielograma) y una punción lumbar; sin menoscabo de las otras pruebas que igualmente coadyuvan con dicho diagnóstico, pero mucho más con la fase terapéutica. Sin perjuicio de esto, igualmente fue posible identificar algunas recomendaciones que se deben considerar al momento de procurar un diagnóstico de LLA.

Keywords: Linfocítica, neoplasia, patología, hemograma, mielograma.

\section{RESUMO}

Na Leucemia Linfoblástica Aguda, também conhecida como Leucemia Linfocítica / Linfoide Aguda (LLA / ALL), glóbulo branco que se reproduz excessivamente, afetando os tipos de linfocitos (células B e células T); mientras que "aguda", que deseja definir qual é a evolução da leucemia rapidamente, e que não é tratado, provavelmente resultam em mortal no poço do tempo. Se trata do paciente mais comum em pediatria; também afetam adultos de todas as edições. No pediatra, esta é a neoplasia mais comum, representando entre 75 e $80 \%$ de todas as leucemias agudas. A incidência determinou determinar com o máximo entre 2 e 5 anos de idade. Com a presente revisão bibliográfica, você pode identificar as alterações dos métodos diagnósticos do LLA, nenhum pecado antes de ter referências de algas aceitas sobre a patologia, seus fatores de risco e sintomas e manifestações clínicas. Os resultados obtidos são constituídos por exposições que variam de experiência para ele sobre este tema, e os mecanismos que satisfazem o objetivo proposto. Em conclusão, por uma parte, se você estiver interessado nos últimos estudos sobre os métodos diagnósticos do LLA, terá mais coincidências de acidentes entre a prefeitura de tratadores que, oficialmente, está vinculando um analista de sangre (Hemograma completo e frações de sangre periférica), um aspirado e biópsia da medula óssea (também chamada lhamado mielograma) e uma punção lombar; se menos do que as outras pruebas, que também são coadjuvantes com diagnóstico, você pode saber mais sobre a fase terapêutica. No caso de um estoiro, também é possível identificar as recomendações recomendadas que podem ser consideradas no momento de procurar um diagnóstico de LLA.

Palavras-chave: Linfocítica, neoplasia, patologia, hemograma, mielograma. 


\section{Introducción}

La leucemia linfoblástica aguda (LLA, O ALL, del inglés: Acute lymphoblastic leukemia) es una enfermedad también conocida como leucemia linfocítica aguda y leucemia linfoide aguda. Esta sucede cuando el cuerpo crea linfoblastos (un tipo de glóbulo blanco) excesivamente, pudiendo perjudicar a dos tipos de linfocitos (las células B y las células T). Esta patología es médicamente diferenciada entre dos subtipos, en función del tipo de linfocitos implicados. (The Nemours Foundation, 2018)

Esta misma institución sostiene que la LLA viene siendo el tipo de cáncer más reincidente en la infancia, y el subtipo que más padecen este grupo etario es el que afecta a las células $B$. En vista de que este padecimiento evoluciona de manera acelerada y en la misma media se agrava, han referido la trascendencia en su temprano diagnóstico, no obstante, los constantes adelantos obtenidos tanto a nivel terapéutico como en los ensayos clínicos, favorecen el pronóstico en pacientes pediátricos puesto que la mayoría que recibe el tratamiento, alcanza a curarse.

Jerry Spivak, como tratadista, asegura que se trata del cáncer más común en pediatría; pero igualmente afecta a adultos de todas las edades. La transformación maligna y la proliferación no controlada de una célula progenitora hematopoyética con diferenciación anormal y de supervivencia prolongada determinan un alto número de blastocitos circulantes, reemplazo de la médula ósea normal por células malignas y posibilidad de infiltración leucémica del SNC y órganos abdominales. Los síntomas son cansancio, palidez, infección, dolor óseo, hematomas de fácil aparición y hemorragias. El examen del frotis de sangre periférica y de la médula ósea suele ser diagnóstico. (Manual MSD, 2017)

En el mismo orden de ideas, Lassaletta
(2016) coincide en que, en edad pediátrica, esta enfermedad es la neoplasia más común, representando entre el 75 y $80 \%$ de todas las leucemias agudas. También, en el $25 \%$ de todos los tumores en menores de 15 años y en el 19\% de todos los quistes de los pacientes con menos de 19 años de edad, se constituyen en LLA.

Paralelamente, su incidencia ha podido determinarse con pico máximo entre los 2 y 5 años de edad.

En cuanto al sexo, la LLA predomina ligeramente en los varones, sobre todo en la edad puberal. Las diferencias geográficas son notables en esta enfermedad: mientras que, en los países menos desarrollados, como Norte de África y Oriente Medio, predominan los linfomas y las LLA de estirpe $\mathrm{T}$, en los países industrializados, la LLA de estirpe $B$ es con diferencia la más frecuente de las hemopatías malignas. Este hecho se ha relacionado con la mayor facilidad para la exposición a determinados agentes medioambientales "leucemógenos" en los países industrializados. En los países con poblaciones heterogéneas, se ha observado una mayor incidencia de LLA en la raza blanca. (Lassaletta, 2016, pág. 381)

Otros datos más recientes son aportados por la Sociedad Norteamericana Contra El Cáncer (2020), y entre estos han destacado que:

- El riesgo de LLA es el mayor en los niños menores de 5 años de edad. Luego el riesgo se reduce lentamente hasta la mitad de los años veinte, y vuelve a elevarse otra vez lentamente después de los 50 años de edad. En general, alrededor de 4 de cada 10 casos de LLA corresponden a adultos.

- El riesgo promedio que tiene una persona de padecer LLA durante su vida es de aproximadamente 1 en 1,000. El riesgo es ligeramente mayor entre los hombres que entre las mujeres, y es mayor

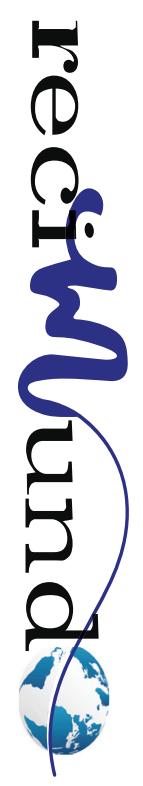


en los estadounidenses de raza blanca que en las de raza negra.

- La mayoría de los casos de LLA ocurren en niños, pero la mayoría de las muertes a causa de esta leucemia (aproximadamente 4 de 5) se presenta en adultos. Los niños pueden reaccionar mejor debido a diferencias en el tipo de LLA de la niñez y la adultez, diferencias en tratamiento (los cuerpos de los niños a menudo pueden manejar un tratamiento agresivo mejor que los adultos) o cierta combinación de éstas.

\section{Materiales y Métodos}

Como el objetivo de este trabajo investigativo ha sido efectuar una revisión a la literatura cientificoacadémica disponible, se estimó realizar varias consultas mediante el uso de algunas bases de datos, tales como: BVS, Intramed, Mediagraphic, SciELO, NCBI y otras; así como también de varios sitios web pertenecientes a importantes organizaciones como la Sociedad Norteamericana Contra El Cáncer, el Instituto Nacional del Cáncer de los Institutos Nacionales de la Salud de los Estados Unidos de Norteamérica, la Sociedad Estadounidense de Oncología Clínica, la Asociación Española de Afectados por Linfoma, Mieloma y Leucemia, el Hospital Infantil Brenner, el Hospital de Investigación Infantil San Judas, entre otros.

La exploración se basó en el uso de las siguientes expresiones "leucemia linfoblástica aguda" y " leucemia linfocítica aguda" que a la par de otros criterios, como por ejemplo: contenido en idioma español e inglés; material bibliográfico de tipo cientificoacadémico, fecha de publicación en el período de los últimos diez años (salvo algunas excepciones); área de investigación en medicina humana y ciencias de la salud; entre otros criterios de selección; constituyeron definitivamente un primer proceso de selección. Luego de ir revisando brevemen- te el contenido de ese lote de documentos y demás ejemplares, se procedió separar solamente aquellos contenidos que cumplían con las características antes referidas para ello ir complementando los resultados de este estudio, es decir, que en concreto se escogieron los contenidos que sirvieran para exponer fundadamente las ideas respecto a la temática planteada.

Ya que, como se ha dicho, la finalidad del presente estudio es la de revisar y recopilar información respecto al diagnóstico de la leucemia linfoblástica (linfocítica) aguda (LLA), se creyó necesario rescatar solamente aquel material bibliográfico que se caracterizase por constituirse como: artículos originales y/o de revisión sistemática, publicados en sitios web de revistas científicas, en versión electrónica o digital; e-books, libros digitalizados, protocolos, consensos, manuales o guías (de Procedimientos) clínicos, boletines informativos, tesis (trabajo investigativo) de grado, posgrado o doctorado; actas de congresos o conferencias; planes, proyectos; y cualquier otro tipo de recurso bibliográfico en formato digital hallados en repositorios de sitios web de organismos, instituciones, entes, organizaciones, sociedades o asociaciones y demás unidades (dependientes o descentralizadas), de carácter nacional e internacional, públicas o privadas; es decir, que incluso se consideraron portales web de sociedades o asociaciones profesionales en el área de la Medicina Humana y Ciencias de la Salud y Oncología; dedicadas a la investigación científica y/o académica.

Se desestimaron: cartas editoriales, anotaciones académicas y otros tipos de contenidos bibliográficos de escaso valor cientificoacadémico y de bajo nivel de evidencia.

Una segunda fase del presente proceso investigativo estuvo definida por la división y distribución de todo el material bibliográfico definitivamente seleccionado entre los integrantes del equipo, que consecuentemente 
estuvo sujeto a una serie de debates de tipo colaborativo. Indudablemente, esos debates fueron posibles luego de que, de manera individual y grupal, dichos contenidos fueran analizados. Finalmente, todas estas acciones sirvieron para aclarar las discrepancias de criterios, debido a que necesariamente se requirió para la definición y desarrollo de todas las opiniones expuestas en este estudio.

\section{Resultados}

Para explicar en qué consiste la leucemia linfocítica aguda (LLA), la Sociedad Norteamericana Contra El Cáncer (2018) comienza diferenciando que, el origen del cáncer es cuando las células en el cuerpo comienzan a crecer en forma descontrolada. Seguido, indica que las leucemias son cánceres que se forman en las células que habitualmente desarrollarían hacia los distintos tipos de células sanguíneas. La leucemia, frecuentemente surge en precoces formas de glóbulos blancos, aunque algunas leucemias inician en otros tipos de células sanguíneas.

En la leucemia linfocítica aguda (o, leucemia linfoblástica aguda, como también asegura se conoce), el término «aguda» se refiere a que es posible que la leucemia evolucione rápidamente, y que, de no ser tratada, probablemente resulte mortal en poco tiempo; mientras que «linfocítico» expresa que se produce de los linfocitos en sus formas tempranas (inmaduras), es decir, de un tipo de glóbulo blanco.

La ALL comienza en la médula ósea (la parte blanda del interior de ciertos huesos en donde se forman las nuevas células de la sangre). Con más frecuencia, la leucemia invade la sangre muy rápidamente. A veces, estas células también se pueden propagar a otras partes del cuerpo, como a los ganglios linfáticos, el hígado, el bazo, el sistema nervioso central (el cerebro y la médula espinal) y los testículos (en los hombres). [...]
Los otros tipos de cáncer que se inician en los linfocitos se denominan linfomas (linfoma no Hodgkin o linfoma de Hodgkin). Aunque las leucemias, como la ALL, principalmente afectan la sangre y la médula ósea, los linfomas principalmente afectan a los ganglios linfáticos u otros órganos (pero pueden también afectar la médula ósea). A veces puede ser difícil saber si un cáncer de los linfocitos es una leucemia o un linfoma. Por lo general, si al menos el $20 \%$ de la médula ósea se compone de linfocitos cancerosos (llamados linfoblastos o simplemente blastos), la enfermedad se considera leucemia. [...]

Por otro lado, la leucemia linfocítica aguda (LLA) generalmente no forma tumores. Generalmente afecta toda la médula ósea del cuerpo y, en algunos casos cuando se detecta, ya se ha propagado a otros órganos, como el hígado, el bazo y los ganglios linfáticos. (Sociedad Norteamericana Contra El Cáncer, 2018)

Ashkan Emadi y Jennie York describen que: En la ALL, las células leucémicas muy inmaduras se acumulan en la médula ósea, destruyendo y reemplazando a las que producen glóbulos sanguíneos normales. Las células leucémicas son transportadas por el torrente sanguíneo hacia el hígado, el bazo, los ganglios linfáticos, el cerebro y los testículos, donde pueden continuar su crecimiento y división. Sin embargo, las células ALL pueden acumularse en cualquier lugar en el cuerpo. Pueden extenderse a la membrana que recubre el cerebro y la médula espinal (meningitis leucémica), y también producen anemia, insuficiencia hepática y renal, y lesiones en otros órganos. (Manual MDS, 2018)

\section{Factores de riesgo de LLA}

Son escasos los factores vinculados con un incremento de riesgo de LLA que ha sido posible identificar, sin embargo, entre los

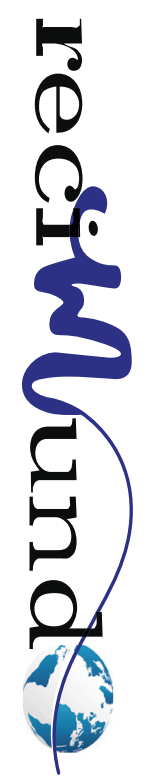


principalmente aceptados y los genes relacionados (cuando sea pertinente) de la LLA se encuentran:

- Exposición prenatal a los rayos X.

- Exposición posnatal a dosis altas de radiación (por ejemplo, la radiación terapéutica, como se solía usar para afecciones como la tiña de la cabeza o hiperplasia tímica).

- Tratamiento previo con quimioterapia.

- Ciertas infecciones virales: virus linfotrópico humano de células T tipo 1 (HTLV1), virus de Epstein-Barr (EBV).

- Incidencia según el sexo: la LLA es ligeramente más común en los hombres que en las mujeres.

- Gemelo idéntico con LLA: una persona que tenga un gemelo idéntico que padece esta enfermedad en el primer año de vida estará en presencia de un mayor riesgo de padecer LLA.

- Las siguientes afecciones genéticas:

- Síndrome de Down.

- Neurofibromatosis.

- Síndrome de Klinefelter.

- Síndrome de Bloom.

- Anemia de Fanconi (múltiples genes; la LLA se observa con mucha menor frecuencia que la leucemia mieloide aguda).

- Ataxia telangiectasia.

- Síndrome de Li-Fraumeni.

- Deficiencia constitucional de reparación de errores de emparejamiento (mutación bialélica en MLH1, MSH2, MSH6 y PMS2).

- Variantes genéticas heredadas de penetrancia alta y baja.
- Los portadores de una translocación robertsoniana constitucional que afecta los cromosomas 15 y 21 están específica y altamente predispuestos a presentar LLA iAMP21. (Instituto Nacional del Cáncer de los Institutos Nacionales de la Salud de los Estados Unidos de Norteamérica, 2019; Sociedad Norteamericana Contra El Cáncer, 2018)

Síntomas y Manifestaciones Clínicas de LLA

- Cansancio, debilidad y palidez (por anemia)

- Aparición de morados y pequeñas manchas rosadas en la piel (petequias) u otros sangrados (por las plaquetas bajas)

- Bultos en el cuello, debajo del brazo, en el estómago o la ingle.

- Fiebre, sudoración excesiva e infecciones, tales como bronquitis o tonsilitis, que no evolucionan bien (mal funcionamiento de los leucocitos)

- Dolor en las articulaciones y los huesos, cojera (por la invasión de la médula ósea por las células leucémicas)

- Adenopatías o aumento de tamaño de los ganglios linfáticos (por ocupación de las células leucémicas)

- Dificultad respiratoria, taquicardia o dolor torácico.

- Dolor abdominal (causado por la acumulación de células sanguíneas anormales en órganos como los riñones, el hígado y el bazo).

- Pérdida del apetito.

- Dolores de cabeza, vómitos, accidente cerebrovascular y alteraciones de la visión, el equilibrio, la audición y los músculos faciales. (Hospital Infantil Brenner, 2012; Manual MDS, 2018; Hospital de Investigación Infantil San Judas, 2018; 
Fundación Josep Carreras, 2020)

\section{Diagnóstico de LLA}

De acuerdo al criterio de expertos de la Sociedad Estadounidense de Oncología Clínica (ASCO, por sus siglas en inglés), en niños, los métodos que fundamentalmente se consideran a la hora de determinar la ALL (e inclusive para el descarte de otras enfermedades) son: los exámenes físicos, la historia clínica del paciente, el hemograma completo, es decir, recuento completo de células sanguíneas ( $\mathrm{CBC}$, derivado del inglés: complete blood cell count), y aspiración de la médula ósea. (ASCO, 2017 a)

\section{Examen físico}

Según la Asociación Española de Afectados por Linfoma, Mieloma y Leucemia (AEAL), con el examen físico el objetivo es verificar los signos generales de salud, signos patológicos, masas o cualquier otro aspecto que se considere irregular. (AEAL, 2017) Revisará cuidadosamente los ojos, la boca, la piel y las orejas. Se puede realizar un examen del sistema nervioso. El médico palpará el abdomen del paciente para detectar signos de agrandamiento del bazo o del hígado. (Hospital de Investigación Infantil San Judas, 2018)

Así mismo se consideran los antecedentes médicos de las enfermedades y los tratamientos previos del paciente. En los antecedentes médicos, los médicos buscan posibles afecciones heredadas que podrían contribuir al desarrollo del cáncer infantil. Sin embargo, los estudios han demostrado que solo entre el 8 y el $10 \%$ de los casos de cáncer infantil son heredados. (AEAL, 2017; Hospital de Investigación Infantil San Judas, 2018)

\section{Análisis de sangre}

Un hemograma completo (CBC) sirve para un recuento de cada tipo de célula de la sangre y además puede dejar ver la presencia de células de leucemia anormales. Para el momento en que se diagnostica en pediatría, casi todos los pacientes con ALL, este examen les resulta con ciertas irregularidades. "Un análisis químico de sangre proporciona información sobre la función renal y hepática del cuerpo y sobre otras mediciones, como los niveles de sal." (ASCO, 2017 a)

Sin embargo, en términos generales, es habitual que de cualquier persona con LLA se detecten bajos niveles de glóbulos rojos y plaquetas, así como también pueden hallarse altos, normales o bajos niveles de glóbulos blancos. Cabe destacar que todas estas variaciones en los niveles de células sanguíneas pueden representar el indicio de otro tipo de afección distinto a la leucemia. Asimismo, es posible que la sangre sea examinada con la finalidad de constatar la existencia de linfoblastos u otras células anormales. (ASCO, 2017 b)

\section{Frotis de sangre periférica}

En este sentido la hace referencia al estudio en el que:

se coloca una gota de sangre en un portaobjetos para analizar las células con un microscopio y así saber cómo lucen. Los cambios en los números y en la apariencia de las células a menudo ayudan a diagnosticar la leucemia. La mayoría de los pacientes con LLA tienen demasiados glóbulos blancos inmaduros llamados linfoblastos (o simplemente blastos) en la sangre e insuficientes glóbulos rojos o plaquetas. Los linfoblastos no se encuentran normalmente en la sangre, y no funcionan como glóbulos blancos normales y maduros. (Sociedad Norteamericana Contra El Cáncer, 2018) 


\section{Aspiración y biopsia de médula ósea}

Se trata de dos técnicas que, al ser tan parecidas, suelen hacerse juntas para analizar la médula ósea que se encuentra constituida por parte líquida y otra sólida. La aspiración se trata de la extracción de una muestra del líquido mediante una aguja, mientras que la biopsia consiste en la extirpación de una pequeña cantidad de tejido sólido, también con una aguja; es algo común que la ubicación anatómica de la que se toman las muestras para estos dos procedimientos sea del hueso pélvico, el cual se sitúa en la región lumbar cercano a la cadera.

Básicamente, la aspiración de la médula ósea es indicada si, en los niños, el especialista sospecha una leucemia, y en general, si posterior al análisis de sangre se evidencia un irregular recuento sanguíneo o si se manifiestan células inmaduras.

\section{Punción lumbar}

La prueba de líquido cefalorraquídeo, como también es conocido este estudio, es posible mediante una punción espinal (lumbar), en la que se extrae una muestra que luego es analizada para determinar si las células cancerosas se propagaron al líquido cefalorraquídeo (LCR). (Clínica Mayo, 2018)

Sin embargo, actualmente no hay exámenes especiales que se recomienden para detectar la leucemia linfocítica aguda (LLA) en sus comienzos. La mejor forma de detectar la leucemia en sus inicios es notificar inmediatamente al médico cualquier signo o síntoma posible de leucemia. (Sociedad Norteamericana Contra El Cáncer, 2018)

\section{Otras pruebas}

Son las que tendrán lugar usando muestras adicionales igualmente obtenidas de la misma médula mediante el referido procedimiento, y entre estas figuran:
Análisis genéticos moleculares y cromosómicos y el inmunofenotipo. Estas son importantes para planificar los tratamientos más adecuados. (ASCO, 2017 a) (ASCO, 2017 b)

\section{Pruebas de Citometrías de Flujo (inmu- nofenotipo) y citoquímica}

Pruebas que se realizan a partir de una muestra de sangre. Se utilizan unos químicos o tintes sobre las células cancerosas para obtener más información sobre la leucemia y su subtipo. Las células de LLA tienen marcadores característicos en su superficie que se denominan proteínas en la superficie de las células. El patrón de estos marcadores se denomina inmunofenotipo. Estas pruebas se utilizan para distinguir la LLA de las células sanguíneas sanas y de otros tipos de leucemia, que también pueden incluir linfocitos. Al analizar las propiedades de las células cancerosas, el especialista puede determinar el tipo y los subtipos de leucemia, información que también es trascendente para el tratamiento el cual varía según el tipo de leucemia. (Hospital Infantil Brenner, 2012; ASCO, 2017 b)

\section{Cariotipificación o citogenética (Análisis Citogenético)}

Al analizar el ADN de la sangre o de la médula ósea, los médicos pueden ver los cambios genéticos específicos de cada subtipo de leucemia linfoblástica aguda. (Hospital Infantil Brenner, 2012) Con este estudio se verifican los cromosomas de una célula. Los cromosomas son segmentos lineales de ADN largos que contienen genes. (ASCO, 2017 b)

Esta prueba, que se ha realiza sobre la muestra de sangre o de tejido de la médula ósea, ha permitido identificar un gran número de alteraciones cromosónicas recurrentes y se considera primordial para la clasificación de los pacientes en las diferentes líneas de tratamiento. Algunas de las 
alteraciones identificadas a través del análisis citogenético están asociadas a características biológicas y clínicas muy concretas, que se han empleado como marcadores diagnósticos y pronósticos y han contribuido a la definición de los grupos de riesgo. (AEAL, 2017)

\section{Ensayos moleculares}

Es posible que estas pruebas sean capaces de encontrar mutaciones en genes que no se pueden ver con un microscopio o mediante pruebas citogenéticas. Por ejemplo, los pacientes con cambios en el gen IKZF1 tienen un peor pronóstico a largo plazo, el cual es la posibilidad de recuperación. Por lo tanto, las pruebas para estos cambios durante el diagnóstico ayudan a determinar las opciones de tratamiento de un paciente. (ASCO, 2017 b)

Hibridación in situ con fluorescencia (FISH) Esta prueba constituye otra forma de examinar los cromosomas y los genes. Utiliza tintes fluorescentes especiales que sólo se adhieren a genes específicos o partes de cromosomas particulares. La prueba FISH puede encontrar la mayoría de los cambios cromosómicos (como translocaciones) que son visibles en un microscopio en las pruebas citogenéticas convencionales, así como algunos cambios que son demasiado pequeños para verlos con la prueba citogenética usual.

La prueba FISH se puede usar en muestras rutinarias de sangre y médula ósea. Debido a que las células no tienen que dividirse para esta prueba, también se puede usar para examinar las células de otros tejidos, como muestras de ganglios linfáticos. Esta prueba es muy precisa y puede usualmente proveer resultados en un plazo corto, sólo unos días. (AEAL, 2017)

Reacción en cadena de la polimerasa (PCR) La reacción en cadena de la polimerasa es una prueba de ADN de alta sensibilidad que también puede encontrar algunos cier- tos cambios cromosómicos tan pequeños que no se pueden ver con el microscopio, aunque la muestra tenga muy pocas células leucémicas. Al igual que la FISH, se usaba para encontrar cambios genéticos particulares y no para examinar los cromosomas en general.

En caso de LLA, se emplea con frecuencia para identificar la presencia del gen producido por el cromosoma Filadelfia.

Si las células leucémicas tienen un cambio genético particular (o cromosoma), se puede emplear la PCR después del tratamiento para tratar de encontrar pequeños números de células leucémicas que pueden no ser visibles con un microscopio. (AEAL, 2017)

Biopsia de los ganglios linfáticos

La extirpación de un ganglio linfático o parte de un ganglio a menudo se realiza para ayudar a diagnosticar los linfomas, pero puede ser necesario, en ocasiones en las leucemias, aunque habitualmente el diagnóstico se puede hacer mediante el análisis de la sangre y la médula ósea.

En este procedimiento un cirujano corta la piel para extirpar todo o parte de un ganglio linfático. Si el ganglio se encuentra cerca de la superficie de la piel, ésta es una operación sencilla que puede hacerse a menudo con anestesia local, pero si el ganglio se encuentra dentro del pecho o del abdomen, se usa anestesia general para mantenerle dormido durante la biopsia.

Cuando se extirpa un ganglio linfático por completo, se le llama biopsia por escisión de ganglio linfático. En caso de que se extirpe una parte de un ganglio linfático, se le llama biopsia por incisión de ganglio linfático. (AEAL, 2017)

\section{Pruebas de diagnóstico por imágenes}

Entre estas destacan las radiografías ( $R x$, las tomografías computarizadas (TC) o las

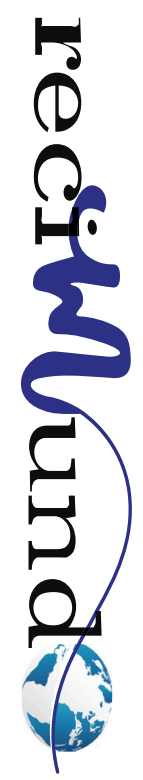


ecografías (ultrasonido), imágenes por resonancia magnética (IRM, o MRI, proveniente de la expresión en inglés: magnetic resonance imaging), tomografía por emisión de positrones (TEP, o PET, proveniente de la expresión en inglés: positron emission tomography), gammagrafía con galio y gammagrafía ósea, con las que es posible determinar, entre otras cosas, la diseminación del cáncer hacia el cerebro y/o la médula espinal u otras partes del cuerpo. (AEAL, 2017; Clínica Mayo, 2018)

\section{Conclusiones}

De conformidad a la literatura consultada, es posible atreverse a inferir dos aspectos fundamentales; por una parte se reconoce que, en los últimos años, las opiniones respecto a los métodos diagnósticos de LLA son más coincidentes de disidentes entre la mayoría de los tratadistas referidos en esta investigación, ya que básicamente estos se vinculan a análisis de sangre (Hemograma completo y frotis de sangre periférica), un aspirado y biopsia de médula ósea (también llamado mielograma) y una punción lumbar; sin menoscabo de las otras pruebas que igualmente coadyuvan con dicha diagnosis, pero mucho más con la fase terapéutica. El otro aspecto a resaltar podría ser lo relacionado tratamiento de esta enfermedad, debido a que en esa área es que más se están materializando los avances científicos, lo que por cierto se encuentra a la par de diversos estudios clínicos pormenorizados.

Sin perjuicio de lo expuesto, igualmente fue posible identificar algunas recomendaciones que se deben considerar al momento de procurar un diagnóstico de LLA, la cuales se refieren a continuación:

- Indistintamente de la edad, las características de la muestra del aspirado ni ausencia o la presencia de pancitopenia; a todos los pacientes con sospecha diagnóstica de LLA, ha de tomarseles biopsia de médula ósea.

- Para un diagnóstico confirmatorio, tomar muestra de sangre periférica, aspirado de médula ósea y biopsia a todos los pacientes, así como también se les debe efectuar un estudio morfológico, inmunológico, genético y biología molecular.

- Separar la muestra en dos tubos: una muestra con 5cc en un tubo con EDTA para el estudio morfológico inmunología y de biología molecular, y la otra de 3cc en un tubo con heparina para citogenética y cariotipo.

- Hacer el diagnóstico morfológico con mielograma con conteo a 500 células.

\section{Bibliografía}

AEAL. (20 de 02 de 2017). ¿Cómo se diagnostica la Leucemia Linfoblástica Aguda? Recuperado el 16 de 05 de 2020, de aeal.es/: http://www.aeal. es/leucemia-linfoblastica-aguda-espana/3-como-se-diagnostica-la-leucemia-linfoblastica-aguda/

ASCO. (Octubre de 2017 a). Leucemia - linfoblástica aguda - ALL - infantil: Diagnóstico. (A. S. (ASCO), Productor) Recuperado el 15 de 05 de 2020, de cancer.net: https://www.cancer.net/ es/tipos-de-c\%C3\%A1ncer/leucemia-linfobl\%C3\%A1stica-aguda-all-infantil/diagn\%C3\%B3sti$\mathrm{CO}$

ASCO. (Mayo de 2017 b). Leucemia - linfocítica aguda - ALL - en adultos: Diagnóstico. Recuperado el 16 de 05 de 2020, de cancer.net: https:// www.cancer.net/es/tipos-de-c\%C3\%A1ncer/leucemia-linfoc\%C3\%ADtica-aguda-all-en-adultos/ diagn\%C3\%B3stico

Clínica Mayo. (10 de Agosto de 2018). Leucemia linfocítica aguda. Recuperado el 17 de 05 de 2020, de mayoclinic.org/: https://www.mayoclinic.org/ es-es/diseases-conditions/acute-lymphocytic-leukemia/diagnosis-treatment/drc-20369083

Fundación Josep Carreras. (20 de 05 de 2020). Leucemia linfoblástica aguda infantil. Recuperado el 20 de 05 de 2020, de fcarreras.org: https://www. fcarreras.org/es/leucemia-linfoblastica-aguda-infantil_1190335

Hospital de Investigación Infantil San Judas. (Junio 
de 2018). Leucemia linfoblástica aguda (LLA). Recuperado el 16 de 05 de 2020, de together.stjude.org/es-us: https://together.stjude.org/es-us/ acerca-del-c\%C3\%A1ncer-pedi\%C3\%A1trico/tipos/leucemia/leucemia-linfobl\%C3\%A1stica-aguda-lla.html

Hospital Infantil Brenner. (Octubre de 2012). Leucemia linfoblástica aguda. Recuperado el 16 de 05 de 2020, de brennerchildrens.org: https:// www.brennerchildrens.org/KidsHealth/Parents/ Cancer-Center/En-espanol/Leucemia-linfoblastica-aguda.htm

Instituto Nacional del Cáncer de los Institutos Nacionales de la Salud de los Estados Unidos de Norteamérica. (08 de Octubre de 2019). Tratamiento de la leucemia linfoblástica aguda infantil (PDQ®). Recuperado el 17 de 05 de 2020, de cancer.gov: https://www.cancer.gov/espanol/tipos/leucemia/ pro/tratamiento-Ila-infantil-pdq\#_12_toc

Lassaletta, A. (Julio-Agosto de 2016). Leucemias. Leucemia linfoblástica aguda. (S. E. SEPEAP), Ed.) Pediatría Integral, XX(6), 380-389. Recuperado el 15 de 05 de 2020, de https://www.pediatriaintegral.es/wp-content/uploads/2016/09/Pediatria-Integral-XX-06_WEB.pdf\#page=32

Manual MDS. (Noviembre de 2018). Leucemia linfocítica aguda. Recuperado el 17 de 05 de 2020, de msdmanuals.com/: https://www.msdmanuals. com/es/hogar/trastornos-de-la-sangre/leucemias/ leucemia-linfoc\%C3\%ADtica-aguda
Manual MSD. (Enero de 2017). Leucemia linfocítica aguda (LLA). (J. Spivak, Editor) Recuperado el 15 de 05 de 2020, de https://www.msdmanuals.com/ es/professional/hematolog\%C3\%ADa-y-oncolog\%C3\%ADa/leucemias/leucemia-linfoc\%C3\%ADtica-aguda-lla: https://www.msdmanuals.com/es/ professional/hematolog\%C3\%ADa-y-oncolog\%C3\%ADa/leucemias/leucemia-linfoc\%C3\%ADtica-aguda-lla

Sociedad Norteamericana Contra El Cáncer. (17 de Octubre de 2018). Acerca de la leucemia linfocítica aguda. Recuperado el 16 de 05 de 2020, de cancer.org: https://www.cancer.org/es/cancer/ leucemia-linfocitica-aguda/acerca/que-es-leucemia-linfocitica-aguda.html

Sociedad Norteamericana Contra El Cáncer. (8 de Enero de 2020). Estadísticas importantes sobre la leucemia linfocítica aguda (ALL). Recuperado el 15 de 05 de 2020, de cancer.org: https://www. cancer.org/es/cancer/leucemia-linfocitica-aguda/ acerca/estadisticas-clave.html

The Nemours Foundation. (Octubre de 2018). Leucemia linfoblástica aguda. (E. Caywood, Editor) Recuperado el 15 de 05 de 2020, de KidsHealth. org: https://kidshealth.org/es/parents/all-esp.html

\section{CITAR ESTE ARTICULO:}
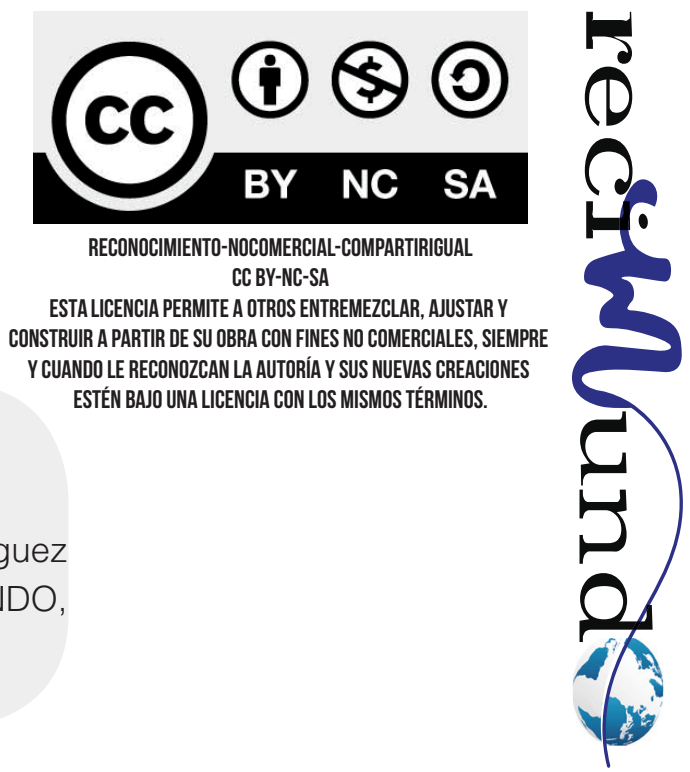

Mancero Rodríguez, M., Arellano Salinas, K., Santo Cepeda, K., \& Rodríguez Revelo, M. (2020). Leucemia linfoblástica aguda diagnostico. RECIMUNDO, 4(2), 53- 63. doi:10.26820/recimundo/4.(2).mayo.2020.53-63 